\title{
Smoking Cessation in the Middle East after Percutaneous Coronary Intervention. Results from the First Jordanian Percutaneous Coronary Intervention Registry (JoPCR1)
}

\author{
Rinad R. Tabbalat', Rawan A. Hammoudeh², Yousef Khader ${ }^{3}$, Ayman J. Hammoudeh ${ }^{*}$ \\ ${ }^{1}$ Department of Internal Medicine, Istishari Hospital, Amman, Jordan \\ ${ }^{2}$ Department of Medical Education, Jordan University of Science and Technology, Irbid, Jordan \\ ${ }^{3}$ School of Allied Medical Sciences, Jordan University of Science and Technology, Irbid, Jordan \\ ${ }^{4}$ Department of Cardiology, Istishari Hospital, Amman, Jordan \\ Email: "a.hammoudeh@istisharihospital.com, "hammoudeh_ayman@yahoo.com
}

Received 18 April 2016; accepted 4 July 2016; published 7 July 2016

Copyright (C) 2016 by authors and Scientific Research Publishing Inc.

This work is licensed under the Creative Commons Attribution International License (CC BY). http://creativecommons.org/licenses/by/4.0/

c) (i) Open Access

\section{Abstract}

Background: Cigarette smoking (CS) is a major risk factor for cardiovascular disease (CVD) in the Middle East. Little is known about the rate of SC in patients following percutaneous coronary intervention (PCI) and the clinical and angiographic features and one-year outcome among quitters compared with persistent smokers. Methods and Results: Of 2425 patients enrolled in a prospective multicenter PCI registry, 1055 (43.5\%) were smokers (mean age $53.7+5.7$ years) and 94\% were males. PCI was indicated for ACS in 862 patients (82\%). The rate of CS was $33 \%, 30 \%$ and $31 \%$, at 1, 6 and 12 months after discharge, respectively. Compared with persistent smokers, quitters were more likely to have diabetes $(50.4 \%$ vs. $42.0 \%$; $p=0.028)$, low left ventricular ejection fraction (18.1\% vs. 9.3\%; $p=0.0004)$, and heart failure $(15.4 \%$ vs. $9.0 \% ; p=0.0008)$. There were no differences between quitters and persistent smokers in age, gender, or severity of coronary lesions. Assessing the major complications and cardiovascular events during the index admission and at one year in non-smokers, quitters and persistent smokers showed that the incidence rates of in-hospital major bleeding events and cardiovascular deaths differed significantly among the three groups of patients ( $p$-value $=0.017$ for major bleeding, and 0.012 for cardiovascular death). The rates of these two complications were significantly higher among non-smokers compared to quitters and persistent smokers, and the rate of major bleeding was almost double in

\footnotetext{
*Corresponding author.
}

How to cite this paper: Tabbalat, R.R., Hammoudeh, R.A., Khader, Y. and Hammoudeh, A.J. (2016) Smoking Cessation in the Middle East after Percutaneous Coronary Intervention. Results from the First Jordanian Percutaneous Coronary Intervention Registry (JoPCR1). World Journal of Cardiovascular Diseases, 6, 202-210. http://dx.doi.org/10.4236/wjcd.2016.67022 
quitters compared to persistent smokers. Moreover, the three groups differed significantly in the rates of major bleeding, cardiovascular death and coronary revascularization after one year of follow-up. The incidence rates of major bleeding and cardiovascular death after one year were the highest among non-smokers followed by quitters and persistent smokers. The rate of coronary revascularization was significantly higher in quitters compared to non-smokers and persistent smokers. Conclusion: The rate of CS among Middle Eastern patients who undergo PCI is around $30 \%$. Comprehensive secondary prevention strategy in such patients should include an effective smoking cessation program that extends beyond hospital discharge. Larger studies that extend the follow-up for several years are needed to document a positive impact of SC on improving cardiovascular outcome.

\section{Keywords}

\section{Smoking Cessation, Acute Coronary Syndrome}

\section{Introduction}

Cigarette smoking is a major risk factor for cardiovascular disease (CVD) in the Middle East [1] [2]. Among Middle Eastern patients admitted with acute coronary syndrome (ACS), 30\% - 50\% are cigarette smokers. This rate reaches up to $70 \%$ in patients younger than 55 years of age [3] [4]. Practice guidelines for the management of patients with ACS recommend counseling smokers to quit smoking before hospital discharge [5] [6]. Studies from the west, have repeatedly demonstrated that the rate of SC remains disappointing despite its proven advantages [7]-[11]. SC rate in Middle Eastern patients who sustain ACS or undergo percutaneous coronary intervention (PCI), and the clinical and coronary angiographic features of those who quit smoking compared with those who continue to smoke, have not been studied in this region. The two published local studies evaluated SC rates among CVD patients but did not address the incidence rates of major cardiovascular events during hospitalization or at one year of follow-up in quitters compared with persistent smokers or non-smokers [12] [13].

We used the recently completed First Jordanian PCI Registry (JoPCR1) [14] to study the rate of SC among Middle Eastern patients who underwent PCI, and to assess the clinical profiles and coronary angiographic features on admission in those who quit smoking compared with persistent smokers and non-smokers. We also used the registry's data to evaluate the cardiovascular outcome at one year in these three groups. The study could have a positive impact on the clinical practice among health care providers in the region by stressing the importance of quitting smoking in such a relatively young population.

\section{Methods}

The first Jordanian PCI Registry (JoPCR1) is a prospective, multicenter study that involved 2425 patients who underwent PCI for ACS or stable coronary artery disease (CAD) in 12 centers (January 2013 to February 2014) and were followed up for one year after the index hospitalization. Patients who were cigarette smokers at enrollment were considered current smokers. Patients who never smoked, and past smokers who quit at least one month prior to enrollment were considered non-smokers. SC was defined as abstinence from cigarette smoking from enrollment to the time of follow up. The rate of quitting smoking was assessed among smokers at 1,6 , and 12 months after hospital discharge during outpatient visits or hospital readmissions, or by phone calls.

Patients were directly questioned whether they quit smoking or not, and if they did; they were asked about the timing of quitting. No laboratory test was performed to ascertain the smoking status. Non-smokers were asked if they acquired the habit of smoking cigarettes during the study period of one year.

The incidence rates of major complications (ventricular tachycardia, heart failure and emergency coronary artery bypass graft surgery) were assessed during the index hospitalization, and the major cardiovascular events (cardiovascular death, stent thrombosis and major bleeding events) were evaluated from admission to one year of follow up. Coronary revascularization and readmission for ACS were assessed from the time of hospital discharge to one year later. Incidence rates of these events were compared in non-smokers, those who quit and persistent smokers. 
ACS was classified as acute ST-segment elevation myocardial infarction (STEMI), or non-ST-segment elevation ACS (NSTEACS), that includes non-ST-segment MI (NSTEMI) and unstable angina (UA). Stable CAD was defined as chronic stable angina or silent ischemia [15]. Stent thrombosis (definite and probable) was defined according to the Academic Research Consortium definition [16], and major bleeding events were defined according to the CRUSADE (Can Rapid risk stratification of Unstable angina patients Suppress AD verse outcomes with Early implementation of the ACC/AHA guidelines) study definition [17]. The study protocol was approved by the institutional review board or ethics committee at each participating center.

IBM SPSS Statistics 20 (IBM Corp., 2011) was used for data entry and analysis. Data were described using means and percentages. Independent $t$ test was used to test differences between the mean of continuous variables between quitters and persistent smokers. Chi-square test was used to test the differences between proportions and test the differences in the rates of in-hospital and one year cardiovascular events between non-smokers, quitters and persistent smokers. A p-value of less than 0.05 was considered statistically significant.

\section{Results}

Of the 2425 patients enrolled, 1055 (43.5\%) were current smokers. Baseline clinical features of these patients are shown in Table 1 . Smokers who underwent PCI in this study were predominantly men and a decade younger than their counterparts in the west. About half of them had hypertension, and one-third had diabetes mellitus or past history of CAD. The majority of smokers (82\%) had PCI for ACS, NSTEACS was more common than STEMI, and half of them had elevated serum levels of cardiac enzymes. One-vessel PCI was performed in the majority of these patients (75\%).

Table 1. Baseline characteristics of current smokers in the JoPCR1 registry.

\begin{tabular}{|c|c|c|}
\hline Feature & $\mathrm{N}$ & $\%$ \\
\hline Mean age (years) \pm SD & $53.7 \pm 5.7$ & - \\
\hline Men & 992 & 94.0 \\
\hline Hypertension & 546 & 51.8 \\
\hline Dyslipidemia & 468 & 44.4 \\
\hline Family history of premature CAD & 462 & 43.8 \\
\hline Mean body mass index $\left(\mathrm{kg} / \mathrm{m}^{2}\right) \pm \mathrm{SD}$ & $27.5 \pm 6.3$ & - \\
\hline Diabetes mellitus & 395 & 37.4 \\
\hline Previous history of CAD & 329 & 31.2 \\
\hline Previous PCI & 229 & 21.7 \\
\hline LVEF $<40 \%$ & 126 & 11.9 \\
\hline Heart failure & 112 & 10.6 \\
\hline ST-segment elevation & 408 & 38.7 \\
\hline ST-segment depression & 180 & 17.1 \\
\hline Elevated cardiac biomarkers & 528 & 50.0 \\
\hline $\begin{array}{l}\text { Diagnosis: } \\
\text {-STEMI } \\
\text {-NSTEACS } \\
\text { - Stable CAD }\end{array}$ & $\begin{array}{l}403 \\
459 \\
193\end{array}$ & $\begin{array}{l}38.2 \\
43.5 \\
18.3\end{array}$ \\
\hline $\begin{array}{c}\text { Number of coronary arteries diseased: } \\
\text {-Single vessel CAD } \\
\text {-Two-vessel CAD } \\
\text {-Three or more vessel CAD }\end{array}$ & $\begin{array}{c}649 \\
309 \\
97\end{array}$ & $\begin{array}{c}61.5 \\
29.3 \\
9.2\end{array}$ \\
\hline $\begin{array}{c}\text { Number of coronary arteries treated: } \\
\text {-Single vessel PCI } \\
\text {-Two-vessel PCI } \\
\text {-Three or more vessel PCI }\end{array}$ & $\begin{array}{c}790 \\
221 \\
44\end{array}$ & $\begin{array}{c}74.9 \\
20.9 \\
4.2\end{array}$ \\
\hline
\end{tabular}

CAD: coronary artery disease, LVEF: left ventricular ejection fraction, NSTEACS: non-STsegment elevation acute coronary syndrome, PCI: percutaneous coronary intervention, STEMI: ST-segment elevation myocardial infarction. 
Quitting smoking was reported by 348 (33\%) smokers at one month, 317 (30\%) at 6 months, and 327 (31\%) at one year. Among the non-smokers, no patient reported acquiring the habit of smoking during the study period.

The risk factors, clinical features and angiographic characteristics of 260 quitters compared with 591 persistent smokers, who had follow-up data at one year, are shown in Table 2. Compared with persistent smokers; quitters had higher prevalence of diabetes mellitus, low left ventricular ejection fraction and heart failure. They also had lower prevalence of previous history of CAD or PCI. We compared these baseline risk profiles and clinical features on admission of the two groups (quitters and persistent smokers) with non-smokers $(\mathrm{N}=1371)$. Non-smokers were older (mean age $62 \pm 10$ years), more likely to be women (32\%), have higher prevalence of diabetes mellitus (64\%), hypertension (70\%), dyslipidemia (52\%), past history of CAD (39\%), and previous PCI (26\%), and underwent more PCI procedures for multivessel CAD during admission (31\%). All p-values $<0.02$.

Major complications and cardiovascular events during the index admission and at one year in non-smokers, quitters and persistent smokers are shown in Table 3. Of the studied in-hospital events, incidence rates of major bleeding events and cardiovascular deaths differed significantly among the three groups of patients (p-value = 0.017 for major bleeding, and 0.012 for cardiovascular death). The rates of these two complications were significantly higher among non-smokers compared to quitters and persistent smokers, and the rate of major bleeding was almost double in quitters compared to persistent smokers. Moreover, the three groups differed significantly in the rates of major bleeding, cardiovascular death and coronary revascularization after one year of follow up. The incidence rates of major bleeding and cardiovascular death after one year were the highest among nonsmokers followed by quitters and persistent smokers. The rate of coronary revascularization was significantly higher in quitters compared to non-smokers and persistent smokers.

\section{Discussion}

The main findings in this study are: 1) about 30\% of Middle Eastern smokers quit smoking after one year of un-

Table 2. Risk factors profiles, clinical features and angiographic characteristics in quitters compared with persistent smokers.

\begin{tabular}{|c|c|c|c|}
\hline Feature & Patients who quit smoking N (\%) & Persistent smokers N (\%) & $\mathrm{p}$ \\
\hline Number of patients & 260 & 591 & - \\
\hline Men & $242(93.1)$ & $560(94.8)$ & 0.41 \\
\hline Mean age (year) \pm SD & $53.6 \pm 5.6$ & $53.9 \pm 6.1$ & 0.64 \\
\hline Diabetes mellitus & $131(50.4)$ & $248(42.0)$ & 0.03 \\
\hline Hypertension & $132(50.8)$ & $308(52.1)$ & 0.78 \\
\hline Dyslipidemia & $108(41.5)$ & $262(44.3)$ & 0.49 \\
\hline Family history of premature CAD & 109 (41.9) & $278(47.0)$ & 0.19 \\
\hline Mean body mass index $\left(\mathrm{kg} / \mathrm{m}^{2}\right) \pm \mathrm{SD}$ & $27.3 \pm 6.4$ & $27.8 \pm 6.7$ & 0.31 \\
\hline Past history of CAD & $60(23.3)$ & $201(34.0)$ & 0.001 \\
\hline Previous PCI & 45 (17.3) & $142(24.0)$ & 0.04 \\
\hline $\mathrm{LVEF}<40 \%$ & 47 (18.1) & $55(9.3)$ & 0.0004 \\
\hline Heart failure & 40 (15.4) & $53(9.0)$ & 0.0008 \\
\hline Elevated cardiac biomarkers & $132(50.8)$ & $297(50.3)$ & 0.95 \\
\hline ST-segment deviation & $152(58.5)$ & $238(57.2)$ & 0.78 \\
\hline $\begin{array}{c}\text { ACS: } \\
\text {-STEMI } \\
\text {-NSTEACS }\end{array}$ & $\begin{array}{l}113(43.5) \\
102(39.2)\end{array}$ & $\begin{array}{l}223(37.7) \\
253(42.8)\end{array}$ & $\begin{array}{l}0.13 \\
0.37\end{array}$ \\
\hline Primary PCI for STEMI & $59(22.7)$ & $130(22.0)$ & 0.89 \\
\hline Multivessel CAD & $105(40.0)$ & $215(36.4)$ & 0.36 \\
\hline Multivessel PCI & $61(23.5)$ & $144(24.4)$ & 0.84 \\
\hline Mean length of stay (days) \pm SD & $2.3 \pm 1.0$ & $2.2 \pm 1.0$ & 0.18 \\
\hline
\end{tabular}

CAD: coronary artery disease, LVEF: left ventricular ejection fraction, NSTEACS: non-ST-segment elevation myocardial infarction, PCI: percutaneous coronary intervention, STEMI: ST-segment elevation myocardial infarction. 
Table 3. In-hospital major complications and one year cardiovascular events in non-smokers, quitters and persistent smokers.

\begin{tabular}{lcccc}
\hline \multicolumn{1}{c}{ Outcomes } & None smokers N (\%) & Quitters N (\%) & Persistent smokers N (\%) & p-value \\
\hline $\begin{array}{l}\text { Number of patients } \\
\text { In-hospital complications: }\end{array}$ & 1371 & 260 & 591 \\
-Ventricular tachycardia & $13(0.95)$ & $2(0.77)$ & $4(0.68)$ & 0.827 \\
-Heart failure & $114(8.3)$ & $25(9.62)$ & $41(6.94)$ & 0.377 \\
-Emergency CABG & $2(0.15)$ & 0 & 0 & 0.528 \\
-Stent thrombosis & $6(0.44)$ & $1(0.38)$ & $2(0.34)$ & 0.948 \\
-Major bleeding & $20(1.46)$ & $1(0.38)$ & $1(0.17)$ & 0.017 \\
-Cardiovascular death & $14(1.02)$ & 0 & 0 & 0.012 \\
Events at one year: & & & $27(4.57)$ & 0.251 \\
-Readmission for ACS & $60(5.19)$ & $19(7.31)$ & $15(2.54)$ & 0.001 \\
-Coronary revascularization & $36(2.67)$ & $18(6.92)$ & $11(1.68)$ & 0.329 \\
-Stent thrombosis & $24(1.77)$ & $8(3.08)$ & $1(0.17)$ & 0.005 \\
-Major bleeding & $24(1.77)$ & $3(1.15)$ & $1(0.17)$ & 0.002 \\
-Cardiovascular death & $32(2.36)$ & & & \\
\hline
\end{tabular}

ACS: acute coronary syndrome, CABG: coronary artery bypass graft surgery.

dergoing PCI, 2) quitters were more likely to have diabetes mellitus, heart failure or low left ventricular ejection fraction compared with persistent smokers, and 3) one year of follow-up was not long enough to show significant cardiovascular benefits among quitters.

SC is ranked among the most powerful secondary prevention strategies of CVD, and is strongly advocated by practice guidelines for the treatment of patients admitted with ACS [5] [6] [18] [19]. SC in post-MI patients reduced cardiovascular mortality, all-cause mortality, recurrent MI, and heart failure hospitalization in patients with left ventricular systolic dysfunction. Persistent smokers remain at greater risk of death, recurrent MI, stent thrombosis and need for coronary revascularization compared with those who quit [20]-[23].

Due to the high prevalence of smoking in our region, and the relatively younger age group of patients admitted with ACS or those who undergo PCI; SC is of significant importance in primary and secondary cardiovascular prevention. Furthermore; smokers in our study have high prevalence of other concomitant cardiovascular risk factors and comorbid diseases, including hypertension, diabetes mellitus, and dyslipidemia, implicating that secondary cardiovascular prevention in such a patient population is complex and multifaceted task that involves life style modification and using multiple medications.

The rate of SC in this studied PCI population was not different from that demonstrated by studies from other regions in the world and ranges between $21 \%$ and $36 \%$ after 6 to 12 months of sustaining an ACS event [7] [8] [10] [19]. Furthermore; studies that assessed the benefit of the use of pharmacotherapy for SC in a population composed entirely of patients hospitalized with acute MI; showed that the SC rates at 1 year were $37 \%$ in smokers who used bupropion and 32\% in the placebo group $(p=0.33)$ [24] [25].

Despite the fact that only one study demonstrated an exceptionally high rate of SC (84\%) [26], quitting rates of $30 \%$ or more are considered "fairly high" [7] [24]. These rates implicate that 70\% of patients do not quit smoking and remain at high risk of future events. A minimal rate of 50\% of SC is probably an acceptable goal [7].

In concordance with other investigators [24]; we did not observe an increase in the rate of SC at early (1 month) or late (1 year) follow up. The SC remained fairly constant at an approximate rate of 30\%. Furthermore; the post-PCI SC rates in our region did not improve in the past 10 - 12 years despite treatment advances. Two local studies, published in 2002 and 2010, showed SC rates of 32.8\% and 29.7\%; respectively [12] [13]. These rates are not different from those that we report in this contemporary study.

Odds of SC are greater when counseling is initiated during hospitalization for MI and supplying patients with discharge recommendations for life style modification, in addition to repeated contacts, usually by telephone, for $\geq 3$ months after discharge [7] [10] [18] [21]. Patients enrolled in our study received SC advice during admission and out-patient clinic visits. The majority of them, however, did not follow a formal in-patient or out-patient SC program.

Although SC is more likely to be successful during the initial hospitalization phase where the smokers are 
under significant stress related to the acute cardiac disease and potential risks of the revascularization procedure; the low rate of quitting smoking in our cohort argues against a positive impact of such stresses on the smoker's decision to quit. We speculate that the contemporary expedited revascularization strategy of early invasive policy provided to the majority of patients admitted with ACS, that results in rapid resolution of chest pain with low incidence of life-threatening complications and a relatively short hospital stay may all negatively affect the SC decision taken by some patients. There is also shorter time of physicians' contact with patients to adequately discuss SC when the hospital stay is on average 1 - 2 days [3] [4] [11]. Lack of a cardiac rehabilitation program can also negatively impact the SC efforts by the medical staff. In fact, a large study found that the strongest predictor of SC post-PCI was participation in such a program during the index hospitalization [27].

Other reasons for low rates of SC after ACS and PCI are physician- and patient-related factors. Physician- related factors include low rate of referral to SC counseling, and hesitation to add a SC medication to a long list of cardiovascular medications. Patient-related factors, such as gender, lower education level, socioeconomic status, depression, lack of motivation, nicotine dependence as measured by number of cigarettes smoked per day and years of smoking, larger amount of smoking, and reluctance to take medications with potential side effects [28] [29].

We observed that smokers who quit smoking were more likely to have diabetes, heart failure, or low left ventricular ejection fraction compared with persistent smokers, implicating that the presence of these comorbidities may have a positive impact on the patient's decision to quit smoking. Physicians are encouraged to enquire about tobacco use at each office visit or readmission to hospital, and to extend a clear SC recommendation to patients who continue to smoke. Physicians can assist their patients to quit smoking through counseling and pharmacotherapy, which are most effective when used in combination. Providing behavior therapy, telephone support, and self-help materials can all help post ACS and PCI patients to quit smoking [24] [28]-[31]. Promoting SC as an important secondary prevention strategy is a task that is not limited to health care providers, and should involve the smokers' families and coworkers, large-scale campaigns, and effective anti-smoking laws [32] [33].

Several observations from the registry can explain the differences in the incidence rates of in-hospital complications and major cardiovascular events in the three groups (quitters, persistent smokers and non-smokers) from hospitalization to one year. Significant changes in the incidence of ventricular tachycardia, heart failure, referral to emergency CABG or stent thrombosis were not expected to occur at lower rates during hospitalization in quitters compared with the other two groups because the positive cardiovascular effects of SC are unlikely to be manifested during the short periprocedural admission period.

Major bleeding events and cardiovascular deaths were significantly higher among non-smokers than the other two groups from hospitalization to one year of follow up. This is most likely due to higher prevalence of independent risk factors for these two adverse events among non-smokers including the older age, higher percentage of women and diabetics, and multivessel PCI [34]-[37]. Extending registries to longer follow up duration (i.e., 5 years or so) and enrolling larger numbers of smokers might be needed to demonstrate hard evidence of cardiovascular benefits among quitters.

This study has few limitations. The findings should be interpreted with caution considering that fact that the study was conducted in tertiary care centers that might offer better care for ACS and PCI patients than other centers. Hence, the conclusions we reached might not represent smoking behavior among smokers treated at other centers in the region. The data used to assess abstinence from smoking were self-reported by smokers and was not substantiated by objective evidence. Hence; possible misreporting of the smoking status could not be ruled out. Furthermore, a minority of patients (1.5\% at one year) could be reached for follow up which could result in selection bias.

\section{Conclusion}

In conclusion, the rate of CS among Middle Eastern patients who undergo PCI is around 30\%. Comprehensive secondary prevention strategy in such patients should include an effective smoking cessation program that extends beyond hospital discharge. Larger studies that extend the follow-up period for several years are needed to document a positive impact of SC on improving cardiovascular outcome.

\section{Acknowledgements}

We would like to thank the members of the JoPCR1 Investigators Group: Abdelbasit Khatib, MD; Abdelfattah 
Al-Nadi, RN; Abeer Al Bashaireh, PharmD; Ahmad Abdulsattar, MD; Ahmad Harassis, MD, FACC; Akram Saleh, MD; Aktham Hiari, MD, FACC; Ali Shakhatreh, MD; Amr Rasheed, MD; AssemNammas, MD, FACC; Ayed Al-Hindi, MD; Azzam Jamil, MD; Bashar Al A'Amar, MD; Batool Haddad, PharmD; Dalal Al Natour, PharmD; Eyas Al Mousa, MD, FACC; GhaidaMelhem, PharmD; Hadi Abu-Hantash, MD, FACC; Hanan Abunimeh, PharmD; Haneen Kharabsheh, PharmD; Hasan Tayyim, PharmD; Hatem Tarawneh, MD, FACC; Hisham Janabi, MD; Husam Khader, RN; Hussein Al-Amrat, MD; Ibrahim Abu Ata, MD, FACC; Ibrahim Jarrad, MD, FESC; Imad Alhaddad, MD, FACP, FACC; Jamal Dabbas, MD; KamelTouqan, MD; Laith Nassar, MD; Lewa Al-Hazaimeh, MD; Mahmoud Eswed, MD; Mahmoud Izraiq, MD; Mazen Sudqi, MD; Medhat Bakri, MD; Mohammad Bakri, MD; Mohamad Jarrah, MD; Mohammed Mohialdeen, MD; MohannadMomani, RN; Monther Hassan, MD; Nadeen Kufoof, PharmD; Najat Afaneh, PharmD; Nael Shobaki, MD; Nidal Hamad, MD, FACC; Nuha Abu-Diak, PharmD; Osama Okkeh, MD; Qasem Al-Shamayleh, MD, FACC; Raed Awaysheh, MD; Ramzi Tabbalat, MD, FACC; Ryad Jumaa, MD; Sahm Gharaibeh, MD; Saleh Eliamat, RN; Yousef Qussous, MD, FACC; Zakaria Qaqa, MD, FACC; and Ziad Abu Taleb, MD.

\section{Funding}

The study was supported by an unrestricted grant from AstraZeneca.

\section{Conflicts of Interest}

Ayman J. Hammoudeh, MD, FACC, the PI of the JoPCR1, is the recipient of an unrestricted grant form AstraZeneca.

\section{References}

[1] Gehani, A.A., Al-Hinai, A.T., Zubaid, M., et al. (2014) for the INTERHEART Investigators in Middle East. Association of Risk Factors with Acute Myocardial Infarction in Middle Eastern Countries: The INTERHEART Middle East Study. European Journal of Preventive Cardiology, 21, 400-410. http://dx.doi.org/10.1177/2047487312465525

[2] Alsheikh-Ali, A.A., Omar, M.I., Raal, F.J., et al. (2014) Cardiovascular Risk Factor Burden in Africa and the Middle East: The Africa Middle East Cardiovascular Epidemiological (ACE) Study. PloS One, 9, e102830. http://dx.doi.org/10.1371/journal.pone.0102830

[3] Hammoudeh, A.J., Izraiq, M., Hamdan, H., et al. (2008) High-Sensitivity C-reactive Protein Is an Independent Predictor of Future Cardiovascular Events in Middle Eastern Patients with Acute Coronary Syndrome. CRP and Prognosis in Acute Coronary Syndrome. International Journal of Atherosclerosis, 3, 50-55.

[4] Saleh, A., Hammoudeh, A.J., Hamam, I., et al. (2012) Prevalence and Impact on Prognosis of Glucometabolic States in Acute Coronary Syndrome in a Middle Eastern Country: The Glucometabolic Abnormalities in Patients with Acute Coronary Syndrome in Jordan (GLORY) Study. International Journal of Diabetes in Developing Countries, 32, $37-43$. http://dx.doi.org/10.1007/s13410-012-0065-3

[5] Roffi, M., Patrono, C., Collet, J.P., et al. (2015) ESC Guidelines for the Management of Acute Coronary Syndrome in Patients Presenting without Persistent ST-Segment Elevation. European Heart Journal, 37, 267-315. http://dx.doi.org/10.1093/eurheartj/ehv320

[6] Amsterdam, E.A., Wenger, N.K., Brindis, R.G., et al. (2014) AHA/ACC Guideline for the Management of Patients with Non-ST-Elevation Acute Coronary Syndromes: A Report of the American College of Cardiology/American Heart Association Task Force on practice Guidelines. Circulation, 130, e344-e426. http://dx.doi.org/10.1161/CIR.0000000000000134

[7] Benowitz, N.L. and Prochaska, J.J. (2013) Smoking Cessation after Acute Myocardial Infarction. Journal of the American College of Cardiology, 61, 533-535. http://dx.doi.org/10.1016/j.jacc.2012.11.017

[8] Chow, C.K., Jolly, S., Rao-Melacini, P., Fox, K.A., Anand, S.S. and Yusuf, S. (2010) Association of Diet, Exercise, and Smoking Modification with Risk of Early Cardiovascular Events after Acute Coronary Syndromes. Circulation, 121, 750-758. http://dx.doi.org/10.1161/CIRCULATIONAHA.109.891523

[9] Scholte op Reimer, W., de Swart, E., et al. (2006) Smoking Behavior in European Patients with Established Coronary Heart Disease. European Heart Journal, 27, 35-41. http://dx.doi.org/10.1093/eurheartj/ehi497

[10] Reid, R.D., Mullen, K.A., Slovinec D’Angelo, M.E., et al. (2010) Smoking \$cessation for Hospitalized Smokers: An Evaluation of the “Ottawa Model”. Nicotine \& Tobacco Research, 12, 11-18. http://dx.doi.org/10.1093/ntr/ntp165

[11] Boggon, R., Timmis, A., Hemingway, H., Raju, S., Malvestiti, F.M. and Van Staa, T.P. (2014) Smoking Cessation Interventions Following Acute Coronary Syndrome: A Missed Opportunity? European Journal of Preventive Cardiology, 
21, 767-773. http://dx.doi.org/10.1177/2047487312460517

[12] Abu-Baker, N.N., Haddad, L. and Mayyas, O. (2010) Smoking Behavior among Coronary Heart Disease Patients in Jordan: A Model from a Developing Country. International Journal of Environmental Research and Public Health, 7, 751-764. http://dx.doi.org/10.3390/ijerph7030751

[13] Hammoudeh, A.J. (2002) Cigarette Smoking Cessation among Jordanians after Sustaining Acute Coronary Events: The Impact of Undergoing Coronary Revascularization. Jordan Medical Journal, 36, 122-125.

[14] Alhaddad, I., Hammoudeh, A., Al Mousa, E., Jarrah, M., Saleh, A., Qaqa, Z., Janabi, J., Kharabsheh, H., Hazaimeh, L. and Khader, Y. (2015) Middle Eastern Patients Undergoing Percutaneous Coronary Intervention: Factors That Impact In-Hospital and One Year Outcome. Results from the First Jordanian PCI Registry (JoPCR 1). European Heart Journal, 36, 764.

[15] Amsterdam, E.A., Wenger, N.K., Brindis, R.G., Casey, D.E., Ganiats, T.G., Holmes Jr., D.R., Jaffe, A.S., Jneid, H., Kelly, R.F., Kontos, M.C., Levine, G.N., Liebson, P.R., Mukherjee, D., Peterson, E.D., Sabatine, M.S., Smalling, R.W. and Zieman, S.J. (2014) AHA/ACC Guideline for the Management of Patients with Non-ST-Elevation Acute Coronary Syndromes: A Report of the American College of Cardiology/American Heart Association Task Force on Practice Guidelines. Circulation, 130, e344-e426. http://dx.doi.org/10.1161/CIR.0000000000000134

[16] Cutlip, D.E., Windecker, S., Mehran, R., Boam, A., Cohen, D.J., van Es, G.E., Steg, P.G., Morel, M.A., Mauri, L., Vranckx, P., Mc Fadden, E., Lansky, A., Hamon, M., Krucoff, M.W. and Serruys, P.W. (2007) On Behalf of the Academic Research Consortium. Clinical End Points in Coronary Stent Trials: A Case for Standardized Definitions. Circulation, 115, 2344-2351. http://dx.doi.org/10.1161/CIRCULATIONAHA.106.685313

[17] Subherwal, S., Bach, R.G., Chen, A.Y., Gage, B.F., Rao, S.V., Newby, L.K., Wang, T.Y., Gibler, W.B., Ohman, E.M., Roe, M.T., Pollack Jr, C.V., Peterson, E.D. and Alexander, K.P. (2009) Baseline Risk of Major Bleeding in NonST-Segment Elevation Myocardial Infarction: The CRUSADE (Can Rapid Risk Stratification of Unstable Angina Patients SUPPRESS Adverse Outcomes with Early Implementation of the ACC/AHA Guidelines) Bleeding Score. Circulation, 119, 1873-1882. http://dx.doi.org/10.1161/CIRCULATIONAHA.108.828541

[18] Van Spall, H.G.C., Chong, A. and Tu, J.V. (2007) Inpatient Smoking-Cessation Counseling and All-Cause Mortality in Patients with Acute Myocardial Infarction. American Heart Journal, 152, 213-220. http://dx.doi.org/10.1016/j.ahj.2007.04.012

[19] Kinjo, K., Sato, H., Sakata, Y., et al. (2005) Impact of Smoking Status on Long-Term Mortality in Patients with Acute Myocardial Infarction. Circulation Journal, 69, 7-12. http://dx.doi.org/10.1253/circj.69.7

[20] Critchley, J.A. and Capewell, S. (2003) Mortality Risk Reduction Associated with Smoking Cessation in Patients with Coronary Heart Disease: A Systematic Review. JAMA, 290, 86-97. http://dx.doi.org/10.1001/jama.290.1.86

[21] Larsen, G.K., Seth, M. and Gurm, H.S. (2013) The Ongoing Importance of Smoking as a Powerful Risk Factor for ST-Segment Elevation Myocardial Infarction in Young Patients. JAMA Internal Medicine, 173, 1261-1262. http://dx.doi.org/10.1001/jamainternmed.2013.6075

[22] Hasdai, D., Garratt, K.N., Grill, D.E., Lerman, A. and Holmes Jr., D.R. (1997) Effect of Smoking Status on the Long-Term Outcome after Successful Percutaneous Coronary Revascularization. The New England Journal of Medicine, 336, 755-761. http://dx.doi.org/10.1056/NEJM199703133361103

[23] Rallidis, L.S., Hamodraka, E.S., Foulidis, V.O. and Pavlakis, G.P. (2005) Persistent Smokers after Myocardial Infarction: A Group That Requires Special Attention. International Journal of Cardiology, 100, 241-245. http://dx.doi.org/10.1016/j.ijcard.2004.08.040

[24] Eisenberg, M.J., Grandi, S.M. and Gervais, A. (2013) Bupropion for Smoking Cessation in Patients Hospitalized with Acute Myocardial Infarction: A Randomized, Placebo-Controlled Trial. Journal of the American College of Cardiology, 61, 524-532. http://dx.doi.org/10.1016/j.jacc.2012.08.1030

[25] Rigotti, N.A., Pipe, A.L., Benowitz, N.L., Arteaga, C., Garza, D. and Tonstad, S. (2010) Efficacy and Safety of Varenicline for Smoking Cessation in Patients with Cardiovascular Disease: A Randomized Trial. Circulation, 121, 221229. http://dx.doi.org/10.1161/CIRCULATIONAHA.109.869008

[26] Perk, J., Hambraeus, K., Burell, G., Carlsson, R., Johansson, P. and Lisspers, J. (2015) Study of Patient Information after Percutaneous Coronary Intervention (SPICI): Should Prevention Programmes Become More Effective? EuroIntervention, 10, e1-e7. http://dx.doi.org/10.4244/EIJV10I11A223

[27] Sochor, O., Lennon, R.J., Bresnahan, J., Croghan, I., Pack, Q., Rodriguez Escudero, J.P., Kara, T., Somers, V., Lopez-Jimenez, F. and Thomas, R. (2012) Trends and Predictors of Smoking Cessation after Percutaneous Coronary Intervention: Experience from Olmsted County, Minnesota, 1999-2010. Journal of the American College of Cardiology, 59, E1882-E1882. http://dx.doi.org/10.1016/S0735-1097(12)61883-X

[28] Dawood, N., Vaccarino, V., Reid, K.J., Spertus, J.A., Hamid, N. and Parashar, S. (2008) Predictors of Smoking Cessation after a Myocardial Infarction: The Role of Institutional Smoking Cessation Programs in Improving Success. Arc- 
hives of Internal Medicine, 168, 1961-1967. http://dx.doi.org/10.1001/archinte.168.18.1961

[29] Kim, H.E., Song, Y.M., Kim, B.K. and Kim, M.H. (2013) Factors Associated with Persistent Smoking after the Diagnosis of Cardiovascular Disease. Korean Journal of Family Medicine, 34, 160-168. http://dx.doi.org/10.4082/kjfm.2013.34.3.160

[30] Hymowitz, N., Cummings, K.M., Hyland, A., Lynn, W.R., Pechacek, T.F. and Hartwell, T.D. (1997) Predictors of Smoking Cessation in a Cohort of Adult Smokers Followed for Five Years. Tobacco Control, 6, S57-S62. http://dx.doi.org/10.1136/tc.6.suppl_2.S57

[31] Gerber, Y., Goldbourt, U. and Drory, Y. (2008) Interaction between Income and Education in Predicting Long-Term Survival after Acute Myocardial Infarction. European Journal of Cardiovascular Prevention \& Rehabilitation, 15, 526-532. http://dx.doi.org/10.1097/HJR.0b013e328304feac

[32] Pipe, A., Eisenberg, M.J., Gupta, A., et al. (2011) Society Position Statement: Smoking Cessation and the Cardiovascular Specialist: Canadian Cardiovascular Society Position Paper. Canadian Journal of Cardiology, 27, 132-137. http://dx.doi.org/10.1016/j.cjca.2010.12.060

[33] Grainger Gasser, A., Welch, C., Arora, M., Reid, R.D., Suskin, N.G. and Stone, J.A. (2015) Reducing Cardiovascular Mortality through Tobacco Control. A World Heart Federation Roadmap. Global Heart, 10, 123-133. http://dx.doi.org/10.1016/j.gheart.2015.04.007

[34] Granger, C.B., Goldberg, R.J., Dabbous, O., Pieper, K.S., Eagle, K.A., Cannon, C.P., Van Der Welf, E., Avezum, A., Goodman, S.G., Flather, M.D. and Fox, K.A. (2013) Global Registry of Acute Coronary Events Investigators. Predictors of Hospital Mortality in the Global Registry of Acute Coronary Events. Archives of Internal Medicine, 163, 2345-2353. http://dx.doi.org/10.1001/archinte.163.19.2345

[35] Mikhail, G.W., Gerber, R.T., Cox, D.A., Ellis, S.G., Lasala, G.M., Orminston, J.A., Stone, G.W., Turco, M.A., Joshi, A.A., Baim, D.S. and Colombo, A. (2010) Influence of Sex on Long-Term Outcomes after Percutaneous Coronary Intervention with the Paclitaxel-Eluting Coronary Stent. JACC: Cardiovascular Interventions, 3, 1250-1259. http://dx.doi.org/10.1016/j.jcin.2010.08.020

[36] James, S., Angiolillo, D.J., Cornel, J.H., Erlinge, D., Husted, S., Kontny, F., Maya, J., Nicolau, J.C., Spinar, J., Storey, R.F., Stevens, S.R. and Wallentin, L. (2010) PLATO Study Group. Ticagrelor vs. Clopidogrel in Patients with Acute Coronary Syndromes and Diabetes: A Substudy from the Platelet Inhibition and Patient Outcomes (PLATO) Trial. European Heart Journal, 31, 3006-3016. http://dx.doi.org/10.1093/eurheartj/ehq325

[37] Wilson, W.M., Andrianopoulos, N., Clark, D., Duffy, S.J., Brennan, A., Harries, I., New, G., Sebastian, M., Loane, P., Reid, C. and Ajani, A.E. (2011) Long-Term Predictors of Mortality after Percutaneous Coronary Intervention in the Era of Drug-Eluting Stents. American Journal of Cardiology, 108, 936-942.

http://dx.doi.org/10.1016/j.amjcard.2011.05.024

\section{Submit or recommend next manuscript to SCIRP and we will provide best service for you:}

Accepting pre-submission inquiries through Email, Facebook, Linkedin, Twitter, etc

A wide selection of journals (inclusive of 9 subjects, more than 200 journals)

Providing a 24-hour high-quality service

User-friendly online submission system

Fair and swift peer-review system

Efficient typesetting and proofreading procedure

Display of the result of downloads and visits, as well as the number of cited articles

Maximum dissemination of your research work

Submit your manuscript at: http://papersubmission.scirp.org/ 